\title{
Pesquisa e pós-graduação em atividade física relacionada à saúde: avanços, hiatos e implicações na intervenção profissional
}

Foi com grande entusiasmo que recebemos o convite da Revista Brasileira de Atividade Física e Saúde para escrever este Editorial, oportunidade singular para que pudéssemos sintetizar e sistematizar algumas ideias e conceitos acerca da temática que foi proposta e com os quais estamos trabalhando ao longo dos últimos anos no Grupo de Pesquisa em Estilos de Vida e Saúde da Universidade de Pernambuco (GPES/UPE). Um aspecto central a discutir é de natureza histórica, pois a intervenção profissional no campo da atividade física e saúde vem sofrendo intensa modificação nas últimas duas décadas, reflexo dos desafios sociais que vem sendo apresentados e da necessidade de reorganização da atenção à saúde em todos os níveis ${ }^{1}$. Outro elemento que precisa ser discutido diz respeito à análise de como a pesquisa, ação investigativa que ocorre fundamentalmente no âmbito da formação pós-graduada, tem produzido conhecimentos e inovações capazes de induzir avanços nas intervenções no campo da atividade física relacionada à saúde. São precisamente estes os dois elementos centrais que apresentamos como roteiro para as reflexões que serão apresentadas neste texto.

Mas, para conferir maior precisão ao ensaio que será apresentado cabe delimitar, inicialmente, que muitas das ilações descritas são fruto da troca de experiências entre pesquisadores mais experientes e com maior vivência na formação inicial e pós-graduada em conjunto com pesquisadores em formação na área de Educação Física. Esta delimitação é importante porque a "atividade física e saúde" não é o objeto concreto e prioritário da intervenção em outras áreas profissionais, mas também não é um objeto exclusivo da Educação Física.

Seria desejável, no entanto, que todos os profissionais de saúde pudessem no âmbito da sua atuação desenvolver intervenções e ações para promoção da atividade física. Isto seria importante porque a promoção da atividade física está posicionada como estratégia prioritária para enfrentamento de um dos principais desafios à saúde das populações no Brasil e no mundo: a elevada carga de adoecimento e morte por doenças crônicas não transmissíveis.

Até a metade da década de 90 havia somente uma perspectiva para a intervenção profissional com foco na "atividade física e saúde", perspectiva baseada num modelo teórico fundado na ideia de que os benefícios para saúde decorrentes da prática de atividades físicas deveriam, necessariamente, ser mediados por adaptações em parâmetros de aptidão física. Um efeito que não poderia ser alcançado sem a adequada prescrição e supervisão de exercícios físicos. Como reflexo, tanto os esforços de pesquisa quanto de formação profissional recaiam nestes temas, a avaliação da aptidão física e a prescrição e supervisão de exercícios físicos dentro de uma perspectiva clínica e um olhar para a saúde 
em nível individual. De fato, ainda nos dias atuais esses são elementos que permeiam, quase que predominantemente, a discussão sobre atividade física e saúde que ocorre no âmbito dos cursos de formação inicial.

A partir da segunda metade da década de 90, a síntese do conhecimento que havia sido produzido no âmbito da inter-relação "atividade física e saúde" permitiu concluir que seria possível observar benefícios para saúde decorrente da prática de atividades físicas de menor intensidade e ou de menor duração do que o preconizado nas diretrizes de prescrição de exercícios físicos para a melhoria da aptidão física. Isto, obviamente, não descartava a importância que os exercícios físicos têm, mas advertiu para a existência de outras possibilidades de intervenção que não vinham sendo exploradas até então, particularmente no Brasil. Uma das exceções no âmbito da pesquisa foram os trabalhos iniciados à época pelo Núcleo de Pesquisa em Atividade Física e Saúde da Universidade Federal de Santa Catarina (NuPAF/UFSC) e que foram pioneiros no Brasil. Todavia, no âmbito da formação inicial, tal debate levou ainda uma década para ser iniciado e ainda hoje parece ser bastante incipiente.

Realizando uma análise bastante superficial dos currículos dos cursos de Educação Física de seis das dez universidades brasileiras mais bem ranqueadas segundo o relatório do "QS University Rankings BRICS", é possível perceber o quanto parecemos estar distantes de termos uma formação minimamente adequada para lidarmos com as demandas atuais no âmbito da inter-relação atividade física e saúde. Apesar de cinco destas instituições apresentarem em suas matrizes curriculares componentes direcionados a discussão de conceitos ou aspectos relacionados à temática, observa-se nitidamente que isto ocupa ainda uma proporção bastante limitada da carga horária total dos cursos. Tal cenário é observado mesmo considerando que a Resolução CNE/CES n ${ }^{\circ} 7$, de 31 de março de 2004, que institui as Diretrizes Curriculares Nacionais para cursos de Graduação em Educação Física estabeleçam que o profissional graduado deva estar qualificado “...para aumentar as possibilidades de adoção de um estilo de vida fisicamente ativo e saudável" ${ }^{3}$

Apesar desta transição lenta e da resposta que parece ser ainda mais lenta em relação aos desafios e demandas sociais, especialmente no tocante aos esforços de pesquisa e de formação de recursos humanos, deve-se reconhecer que uma transformação difusa vem ocorrendo. Iniciativas recentes como a fundação da Associação Brasileira de Ensino da Educação Física para a Saúde (ABENEFS) constituem uma clara sinalização de que a área está comprometida com a necessidade de uma intervenção mais qualificada e efetiva no tocante à atividade física e saúde. Sem dúvida, a criação da ABENEFS foi um passo importante para que se possa perseguir a adequação da formação profissional na área de Educação Física em relação ao Sistema Único de Saúde (SUS) ${ }^{4}$. Similarmente, a fundação da Sociedade Brasileira de Atividade Física e Saúde (SBAFS), em 2003, constituiu igualmente um marco para reorientação dos esforços de pesquisa em torno do binômio "atividade física e saúde" e neste sentido muitos avanços vêm sendo conquistados 5 .

Mas, diante da constatação deste esforço difuso de reorganização da formação de recursos humanos e do aumento da produção de conhecimento em atividade física e saúde, surgem outras inquietações que precisam ser enfrentadas: estes esforços, particularmente no âmbito da pesquisa, estão melhoran- 
do a formação inicial? Ou, noutro sentido, tais esforços tanto de formação de recursos humanos quanto de pesquisa estão melhorando a intervenção profissional no âmbito da "atividade física e saúde"? Discutir as respostas a estas questões é fundamental para que possamos identificar os avanços que foram alcançados e entender o percurso que ainda precisa ser realizado a fim de qualificar tanto a formação inicial, quanto as intervenções desenvolvidas nos diferentes níveis atenção à saúde.

\section{O hiato entre a pesquisa e a intervenção profissional}

Não há dúvida de que ocorreu um notório incremento da produção científica na área da "atividade física e saúde" nos últimos anos, crescimento este que foi uma resposta à tendência de aumento do número de grupos de pesquisa e de programas de pós-graduação com áreas de concentração ou linhas de pesquisa direcionadas à investigação em atividade física e saúde ${ }^{5}$. A pergunta que emerge é se esta ampliação no corpo de conhecimento resultou em uma intervenção profissional mais efetiva, mais qualificada? Ora, em várias áreas profissionais, inclusive a Educação Física, não é uma constatação difícil a existência de um hiato entre a pesquisa e a intervenção. Por vezes, percebe-se uma desconexão bastante destacada entre o esforço de investigação e as demandas enfrentadas pelos profissionais que estão no mercado de trabalho. À primeira vista, esta falta de sintonia poderia ser somente o reflexo da cultura profissional que não está, via de regra, apoiada no uso do conhecimento como elemento estruturante e qualificador das intervenções. Mas esta explicação seria simplista e possivelmente outros tantos fatores deveriam ser também explorados como explicações razoáveis para este problema.

Outro fator que poderia ser apresentado é a quase absoluta desconexão entre o esforço de pesquisa e a geração de novos recursos para apoiarem uma intervenção mais efetiva e qualificada. Isto nos remete a necessidade de discutir neste ponto o conceito de inovação e sua relação com a pesquisa, além de analisar como uma aproximação entre estas ações (pesquisa, desenvolvimento e inovação) pode repercutir numa melhoria das intervenções em atividade física e saúde. Para efeito de alinhamento conceitual, embora muitas definições possam ser apresentadas, adota-se aqui o entendimento de que inovação diz respeito à transformação de conhecimentos em novos recursos. Parece inequívoca a constatação de que o esforço de pesquisa realizado no âmbito da atividade física e saúde tem gerado acumulação de conhecimentos, mas estes não têm sido transformados em novos recursos que possam apoiar intervenções profissionais mais efetivas. Parece residir neste ponto um dos grandes desafios da atualidade para todos os atores envolvidos, pesquisadores e profissionais.

Não se trata aqui de apresentar uma visão pessimista, enxergando o copo meio vazio ao invés de um copo meio cheio, mas é preciso refletir sobre o esforço que pode ser efetuado a fim de aproximar ainda mais a pesquisa da intervenção em atividade física e saúde. Avanço que dependerá, em nosso entendimento, da adoção de duas estratégias importantes: (1) estímulo à inovação como elemento capaz de qualificar e orientar o esforço de investigação, nesse sentido, não bastaria somente a produção de novos conhecimentos, mas sobretudo de saberes que possam apoiar a inovação, a produção de novos recursos para a intervenção e para a formação de recursos humanos; e, (2) estimulo à uma atuação 
profissional apoiada na apropriação continua dos conhecimentos produzidos na área ou como se costuma rotular uma intervenção baseada em evidências.

Neste cenário, pode-se reconhecer que muitos grupos de pesquisa da área estão empreendendo esforços a fim de alinhar cada vez mais os projetos de pesquisa em desenvolvimento às demandas do contexto real de vida. Por exemplo, poderíamos citar o estudo desenvolvido pelo Grupo de Estudos e Pesquisas Epidemiológicas em Atividade Física e Saúde da Universidade de São Paulo (GEPAF/USP) que desenvolveu uma intervenção para testar modos de atuação profissional na $\mathrm{ABS}^{6}$. O estudo liderado pelo prof. Markus Nahas, intitulado projeto Saúde na $\mathrm{Boa}^{7}$ apresentou resultados indicando que ações relativamente simples, como o oferecimento de material e treinamento para professores, podem melhorar diversos indicadores de saúde em estudantes do ensino médio (i.e, redução da inatividade física). Outro exemplo no mesmo sentido foram os estudos realizados pelo Grupo de Estudos em Epidemiologia da Atividade Física da Universidade Federal de Pelotas (GEEAF/UFPel) orientados a qualificação da intervenção com foco na promoção da atividade física em Unidades Básicas de Saúde (projeto UBS+Ativa) e nas escolas (Educação Física +: Praticando Saúde na Escola) ${ }^{8}$.

Além dos esforços de pesquisa, pode-se destacar também os esforços para repensar a formação profissional, como a experiência relatada de problematização da discussão sobre saúde mental na formação inicial em educação físi$\mathrm{ca}^{9}$ uma temática usualmente negligenciada na formação de profissionais de saúde. Ainda na formação inicial, pode-se citar a implantação do Programa de Educação pelo Trabalho em Saúde (PET-Saúde) em muitas instituições de ensino superior brasileiras, possibilitando aos estudantes de graduação uma maior aproximação com a realidade da intervenção nos serviços de saúde oferecidos no $\mathrm{SUS}^{10}$. Outro importante avanço foi a abertura das residências multiprofissionais (saúde coletiva, saúde da família e saúde mental) com vagas para diferentes profissionais de saúde, inclusive da Educação Física. Uma oportunidade de formação continuada caracterizada principalmente pela lógica da formação de recursos humanos em serviço ${ }^{11}$.

Realizando um resgate das questões norteadoras levantadas no início do presente texto não resta dúvida que é muito difícil dimensionar se todos esses esforços realizados no âmbito da pesquisa e da formação pós-graduada têm repercutido em melhoria da formação inicial e, por conseguinte, da intervenção profissional. Apesar de reconhecer que alguns avanços vêm sendo notados, parece inequívoco que há ainda um longo caminho a percorrer.

\section{CONSIDERAC̣̃ES FINAIS}

Nas últimas duas décadas a intervenção do profissional de Educação Física tem passado por acentuadas transformações no que diz respeito a intervenção com foco na inter-relação atividade física e saúde. $\mathrm{O}$ aumento exponencial no corpo de conhecimento acerca da temática fez com que os antigos modelos de intervenção voltados para melhoria da saúde através de aspectos da aptidão física tenham sido repensados, porém não abandonados. $\mathrm{O}$ crescimento no número de grupos de pesquisa dedicados à temática contribuiu para o preenchimento de importantes lacunas de conhecimento, mas a transformação de tais conhecimentos em novos recursos para apoiar as intervenções representa 
ainda um desafio a ser superado, o desafio da inovação.

Apesar da ampliação das oportunidades de formação continuada que podem contribuir para melhoria da qualidade das intervenções, na formação inicial a tematização da atividade física e saúde parece ser ainda incipiente e, quando existente, centrada predominantemente num modelo de intervenção com foco quase que exclusivo no exercício físico e na aptidão física. A discussão sobre o papel das atividades físicas na melhoria de indicadores de saúde é um hiato a ser superado, tanto no âmbito da investigação quanto da formação inicial e pós-graduada.

\section{REFERÊNCIAS}

1. Loch, MR. A promoção da saúde e a formação inicial do profissional de saúde: desafios e possibilidades. Saúde e meio ambiente: revista interdisciplinar. 2015 . 4:1, 3-16.

2. BRICS. The top 200 universities in BRICS 2015. Disponível em: http://www. topuniversities.com/university-rankings/brics- rankings/2015.

3. Brasil. Ministério da Educação. Diretrizes Curriculares Nacionais para os cursos de graduação em Educação Física, em nível superior de graduação plena: Resolução $\mathrm{N}^{\circ}$ 7. 2004 Mar 31. Disponível em: http://portal.mec.gov.br/cne/arquivos/pdf/ ces0704edfisica.pdf. Acessado em: 26 de agosto de 2015.

4. Fonseca SP, Menezes AS, Loch MR, Feitosa WMN, Nahas MV, Nascimento JV. Pela criação da Associação Brasileira de Ensino da Educação Física para a Saúde: ABENEFS. Rev Bras Ativ Fis e Saúde. 2011; 16: 283-288.

5. Nahas MV, Garcia LMT. Um pouco de história, desenvolvimentos recentes e perspectivas para a pesquisa em atividade física e saúde no Brasil. Rev. bras. Educ. Fís. Esporte. 2010; 24: 135-48.

6. Salvador EP, Ribeiro EH, Garcia LMT, Andrade DR, Guimarães VMV, Aoki MS, et al. Interventions for physical activity promotion applied to the primary healthcare settings for people living in regions of low socioeconomic level: study protocol for a non-randomized controlled trial. Arch Public Health. 2014; 72: 1-12.

7. Nahas MV, Barros MV, Assis MA, Hallal PC, Florindo AA, Konrad L. Methods and participant characteristics of a randomized intervention to promote physical activity and healthy eating among brazilian high school students: the Saude na Boa project. J Phys Act Health. 2009; 6: 153-62.

8. Spohr CF, Fortes MO, Rombaldi AJ, Hallal PC, Azevedo MR. Atividade física e saúde na Educação Física escolar: efetividade de um ano do projeto "Educação Física +". Rev Bras Ativ Fis e Saúde. 2014; 19: 300-313.

9. Silva JRA, Andrade MLSS, Brito ALS, Hardman CM, Oliveira ESA, Barros MVG. Atividade física e saúde mental: uma experiência na formação inicial em Educação Física. Rev Bras Ativ Fis e Saúde. 2014; 19: 133-140.

10. Brasil. Ministério da Saúde. Ministério da Educação. Portaria Interministerial $\mathrm{n}^{\circ}$ 1.802. 2008 Ago 26. Disponível em: http: //portal.saude.gov.br/portal/arquivos/pdf/ portariainterm1802260808.pdf> Acessado em: 25 de agosto de 2015.

11. Loch MR, Florindo AA. A Educação Física e as residências multiprofissionais em saúde. Rev. Bras. Ativ. Fis. Saúde. 2012; 17: 81-2. 